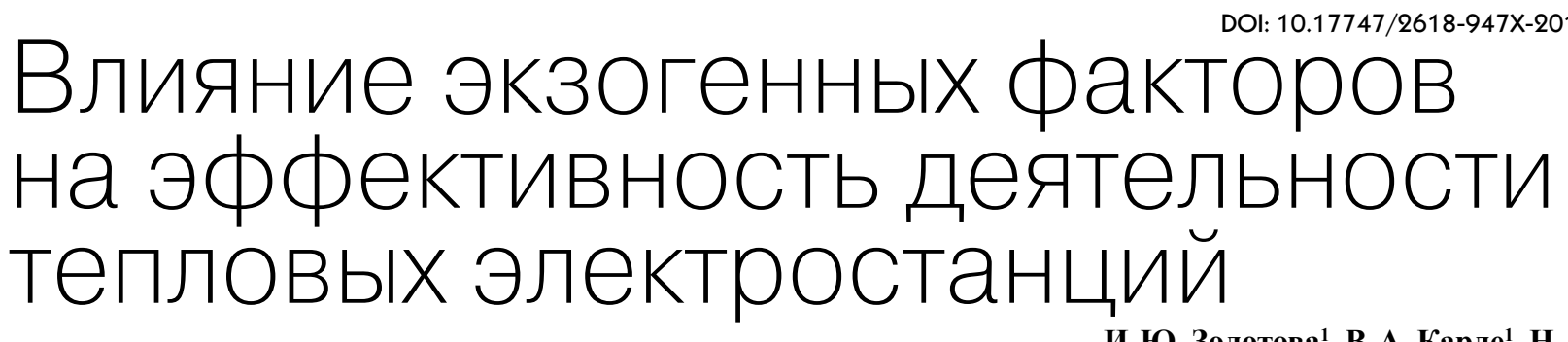

И. Ю. Золотова ${ }^{1}$, В. А. Карле ${ }^{1}$, Н. А. Осокин ${ }^{1}$ АННОТАЦИЯ

${ }^{1}$ ФГОБУ ВО «Финансовый университет при Правительстве Российской Федерации».

бъектом исследования является влияние экзогенных факторов (на которые хозяйственный субъект не может воздействовать напрямую) на показатели эффективности отечественных тепловых электростанций. В качестве показателя эффективности топливоиспользования применен коэффициент использования топлива. В качестве экзогенных факторов приняты климатические условия и вид используемого на станциях топлива. Климатические условия выражены с помощью климатических зон. Анализ причинно-следственных связей между экзогенными факторами и эффективностью станций был проведен с помощью линейной регрессионной модели. Станции, использующие природный газ в качестве основного вида топлива, оказались более эффективны по сравнению со станциями, потребляющими угольное топливо. Статистическая значимость климатического фактора выражена в том, что наивысший коэффициент использования топлива (порядка 71\%) имеют станции, расположенные в третьей климатической зоне (преимущественно в Центральном и Северо-Западном федеральных округах). Рассмотренные экзогенные факторы примерно на 20\% объясняют эффективность топливоиспользования на отечественных тепловых электростанциях. Данные факторы необходимо учитывать при построении аналитических моделей для изучения энергоэффективности отечественных электростанций.

КАЮЧЕВЫЕ САОВА:

электроэнергетика, расходы топлива, энергоэффективность, коэффициент использования топлива, комбинированная выработка тепловой и электрической энергии, тепловые электростанции.

АИЯ ЦИТИРОВАНИЯ:

Золотова И. Ю., Карле В.А., Осокин Н. А. Влияние экзогенных факторов на эффективность деятельности тепловых электростанций // Стратегические решения и риск-менеджмент. 2019. T. 10. № 1. C. 174-181 DOI: 10.17747/2618-947X-2019-2-174-181

\title{
The effect of exogenous factors on thermal power plant efficiency
}

ABSTRACT

IrinaYu. Zolotova ${ }^{1}$, Vadim A. Karle ${ }^{1}$, Nikita A. Osokin ${ }^{1}$

${ }^{1}$ Financial University under the Government of the Russian Federation

T 1 his study focuses on the relationship between exogenous factors (that cannot be directly impacted by the actions of an economic agent) and combined heat and power (CHP) plant efficiency. As a measure of fuel utilization efficiency this paper proposes to use the Coefficient of Fuel Utilization (CFU), which is the Russian equivalent of the Primary Energy Factor indicator. Climate conditions and fuel type were used as the exogenous factors in this article. Climate conditions were measured via climate zone proxies. The causeeffect relationships were analyzed using a linear regression model. The findings of the study showcase that the plants, which use natural gas as their primary fuel, show higher fuel utilization efficiency compared to coil plants. Climate conditions were also proven to be a statistically significant factor with plants situated in the third climate zone (mostly regions of the Central and North-Western federal districts) showing the highest average CFU of about $71 \%$. The research shows that the exogenous factors account for close to $20 \%$ of CHP plant fuel utilization efficiency in Russia. The authors conclude that climate conditions and fuel type should be taken into account when constructing various energy efficiency models applicable to the Russian context.

\section{KEYWORDS:}

electric energy, fuel utilization, energy efficiency, primary energy factor, combined heat and power production, thermal power plants.

\section{FOR CITATION:}

Zolotova, I. Yu., Karle V. A., Osokin N. A. The effect of exogenous factors on thermal power plant efficiency. Strategic Decisions and Risk Management. 2019;10(1):174-181 DOI: 10.17747/2618-947X-2019-2-174-181 


\section{BBEAEHИE}

Повышение энергетической эффективности является одним из ключевых приоритетов российской экономики. В электроэнергетике основным направлением повышения энергоэффективности является снижение расходов топлива при производстве электрической и тепловой энергии, главным образом в режиме комбинированной выработки. Тепловые электростанции, вырабатывающие и электрическую, и тепловую энергию, составляют около $70 \%$ от общей установленной мощности электростанций, работающих на органическом топливе.

За последние 7 лет удельный расход условного топлива (УРУТ) на производство электроэнергии снижен с 334,4 до 311,2 г.у.т./кВт·ч (-23 г, или 7\%) по России в целом (исходя из пропорционального метода разделения расходов топлива между электрической и тепловой энергией) (Теплоэнергетика, 2018). Целевые значения топливной эффективности отечественной энергетики прописаны в «Комплексном плане мероприятий по повышению энергетической эффективности экономики Российской Федерации», утвержденном распоряжением Правительства Российской Федерации от 19.04.2018 № 703-р (Распоряжение, 2018). В частности, плановый показатель УРУТ на производство электрической энергии на ближайшие годы составляет 300 г.у.т. /кВт·ч (-10 г от текущего уровня к 2021 году). На долгосрочную перспективу целевая величина удельного расхода топлива установлена в размере 255,6 г.у.т./кВт·ч к 2035 году. Таким образом, перед отечественной энергетикой стоит серьезная задача по снижению УРУТ в течение ближайших 17 лет более чем на 10\%. Достижение подобного результата зависит не только от реализации мероприятий инвестиционного характера, но и от изменения подходов к загрузке электростанций, оптимизации режимно-балансовых показателей. Кроме того, повышение эффективности топливоиспользования неразрывно связано с формированием системы оценки и контроля соответствующих показателей. На сегодняшний день государственное регулирование инфраструктурных отраслей тяготеет к масштабному введению эталонного принципа в определении отдельных показателей функционирования хозяйствующих субъектов. Методику установления единых (эталонных) значений показателей топливной эффективности для электростанций необходимо ввести в рамках реализации целевого стратегического направления по повышению энергоэффективности экономики страны.

В общем случае эталон понимается как предельно эффективная величина, учитывающая ряд объективных экзогенных факторов. В данной статье экзогенные факторы факторы, на наличие и величину которых не могут оказывать влияние хозяйствующие субъекты. Мы рассматриваем влияние отдельных внешних факторов, в том числе климатических условий, на топливную эффективность отечественных электростанций. Учет соответствующих переменных при эталонировании показателей оценки эффективности топливоиспользования позволит предотвратить принятие недостижимых эталонных значений эффективности использования топлива на электростанциях.

\section{2. ОЦЕНКА ТОПАИВНОЙ ЭФФЕКТИВНОСТИ КОГЕНЕРАЦИОННЫХ ЭАЕКТРОСТАНЦИЙ}

При комбинированном производстве электрической и тепловой энергии принято распределять общий расход топлива между электрической энергией, отпускаемой с шин электростанций, и тепловой энергией, отпускаемой с коллекторов. В отечественной практике для этого применяются физический, пропорциональный и «тепловой» методы разнесения. В общем случае право выбора метода распределения расхода топлива между видами энергии лежит на регулируемых организациях/электростанциях.

Все перечисленные методы предполагают оценку эффективности использования топлива по видам вырабатываемой энергии (электроэнергия или тепловая энергия). Для сравнения: за рубежом топливная эффективность когенерационных станций рассматривается как интегральный показатель, учитывающий и электрическую, и тепловую энергию. В США оценка эффективности использования топлива при комбинированной выработке производится без дифференциации по видам вырабатываемой энергии (Methods, [s.a.]). В частности, используются показатели полной системной эффективности (Total System Efficiency) и эффективность полезной выработки электроэнергии (Effective Electric Efficiency). Первый показатель равнозначно оценивает вклад выработки электроэнергии и отпуска тепла в эффективность топливоиспользования. Подобный подход целесообразнее применять для сравнения эффективности когенерационных станций различного типа. В Европейском Союзе преимущественно используется показатель первичной энергии (Primary Energy Factor), который оценивает объем ресурсов, использованных для производства единицы электро-/теплоэнергии.

В отечественной практике аналогом подобных показателей является коэффициент использования топлива (КИТ). С помощью КИТ оценивается эффективность когенерационных станций типа ТЭЦ. Например, В.Н. Чурашевым было проведено сравнение деятельности станций в Новосибирской и Кемеровской областях за счет применения КИТ (Чурашев, 2016). В работе А. А. Гавриловой КИТ был использован как один из трех ключевых показателей эффективности деятельности когенерационных станций наравне с расходами электроэнергии на собственные нужды и себестоимостью генерации энергии (Гаврилова, 2015).

\section{3. ЭФФЕКТИВНОСТЬ ТОПАИВОИСПОАЬЗОВАНИЯ И КАИМАТИЧЕСКИЙ ФАКТОР}

Российская Федерация расположена в четырех климатических поясах. Это в определенной степени усложняет управление эффективностью ключевых отраслевых комплексов отечественной экономики, в том числе отраслей топливно-энергетического комплекса. 
Влияние климатического фактора на эффективность электростанций неоднократно обсуждалось в литературе. При оценке эффективности когенерационных электростанций необходимо учитывать разную продолжительность отопительного периода, температурные значения в осенне-зимний период, в т. ч. пиковые зоны тепловой нагрузки и их продолжительность. Предложено дифференцировать субъекты Российской Федерации по структуре и уровню тепловой нагрузки в зависимости от плотности населения (Beселов, Волкова, Курилов и др., 2010).

В состав климатических характеристик регионов входят:

- средняя температура в отопительный период;

- среднегодовая продолжительность периода отрицательных температур;

- доля периода отрицательных температур в отопительный период (Филиппов, Дильман, 2014).

При исследовании эффективности теплофикации отечественных электростанций Е.А. Волкова и соавторы (Волкова, Макарова, Хоршев и др., 2010) распределили их среди пяти климатических зон с учетом климатического и географического факторов, которые тесно связаны между собой. На основе расчетной температуры наружного воздуха, принимаемой при проектировании систем отопления, предложены следующие зоны: Юг $\left(-20^{\circ} \mathrm{C}\right)$, Центр $\left(-25^{\circ} \mathrm{C}\right)$, Урал-1 $\left(-30^{\circ} \mathrm{C}\right)$, Урал-2 $\left(-35^{\circ} \mathrm{C}\right)$ и Сибирь $\left(-40^{\circ} \mathrm{C}\right)$.

Важность учета погодно-климатического фактора отмечена при изучении эффективности работы когенерационных электростанций Китая, который также охватывает несколько климатических поясов. Для контроля влияния погодных условий регионы страны были разделены на пять климатических зон в соответствии с национальным стандартом GB 50176-93. На основе средних температурных значений в январе и июне регионы разделены на следующие зоны: сильный холод, умеренный холод, жаркое лето и холодная зима, умеренный климат, жаркое лето и теплая зима (Jiang-Jiang, Chun-Fa, You-Yin, 2010).

В исследованиях западных ученых чаще всего можно найти несколько иной подход к анализу взаимосвязи климатического фактора и эффективности электростанций. В США и ЕС стоит задача снижения негативных экологических последствий от выработки энергии. В литературе рассматривают, насколько эффективны будут электростанции различных типов в условиях глобальных климатических изменений (Allan, Eromenko, Gilmartinetal, 2015). Американские и европейские ученые рассматривают в большей степени влияние топливно-энергетического комплекса на состояние климата, нежели исследуют обратную зависимость.

\section{METOAИKA}

С целью выявить статистически значимые зависимости между внешними (экзогенными) факторами и топливной эффективностью отечественных когенерационных электростанций мы использовали линейную регрессионную модель, построенную методом наименьших квадратов. Данный подход позволяет изучить влияние одной или нескольких независимых переменных (факторов) на исследуемую зависимую переменную (результирующий показатель). Ме- тод наименьших квадратов часто применяется в качестве факторного анализа в эмпирических экономических исследованиях в рамках топливно-энергетического комплекса (Suganthi, Samuel, 2012). Данные о результатах деятельности отечественных когенерационных электростанций были получены по запросу от Министерства энергетики Российской Федерации (в рамках исполнения научно-исследовательской работы № 18/0411.3070390019.241/09/210 в интересах Министерства энергетики Российской Федерации).

\section{1. ЗАВИСИМАЯ ПЕРЕМЕННАЯ}

С учетом подходов к оценке эффективности топливоиспользования на тепловых электростанциях мы предлагаем использовать в качестве зависимой переменной КИТ. Он представляет собой отношение тепловых эквивалентов тепловой и электрической энергии, отпущенных от ТЭЦ, к тепловому эквиваленту сожженного топлива:

$$
U_{i}=\frac{0,86 E_{\text {огі }}+Q_{\text {огі }}}{7 B_{i}} 100 \%,
$$

Где $E_{\text {оті }}$ - объем отпущенной электроэнергии с шин $i$-й электростанции, МВт·ч; $Q_{\text {отi }}$ - объем отпущенной тепловой энергии с коллекторов $i$-й электростанции, Гкал; $B_{i}$ - количество сожженного топлива, т.у.т., на $i$-й электростанции.

\section{2. НЕЗАВИСИМЫЕ ПЕРЕМЕННЫЕ}

С целью учесть природно-климатическую специфику функционирования электростанций было использовано расположение электростанций в рамках конкретной климатической зоны (Постановление, 2010). Классификация регионов России по различным зонам в зависимости от природно-климатических особенностей соответствующих территорий, в том числе с учетом средней температуры, влажности и иных характеристик. Использование зонального подхода к учету климатических особенностей достаточно распространено в зарубежных исследованиях. Принадлежность электростанции к определенной климатической зоне учтена в модели путем введения соответствующих фиктивных переменных (табл. 1).

В первой климатической зоне представлены только станции, использующие газ в качестве основного вида топлива.

Таблица 1

Описание технической структуры электростанций, расположенных в различных климатических зонах

\begin{tabular}{|c|c|c|c|c|}
\hline \multirow{2}{*}{$\begin{array}{c}\text { Клима- } \\
\text { тическая } \\
\text { зона }\end{array}$} & \multirow{2}{*}{$\begin{array}{l}\text { Кодиров- } \\
\text { ка пере- } \\
\text { менной }\end{array}$} & \multicolumn{3}{|c|}{ Число станций в выборке } \\
\hline & & Уголь & Газ & Всего \\
\hline 1 & Climate 1 & 0 & 10 & 10 \\
\hline 2 & Climate 2 & 1 & 3 & 4 \\
\hline 3 & Climate 3 & 1 & 24 & 25 \\
\hline 4 & Climate 4 & 8 & 25 & 33 \\
\hline 5 & Climate 5 & 21 & 11 & 32 \\
\hline \multicolumn{2}{|c|}{ ИТОГО } & 31 & 73 & 104 \\
\hline
\end{tabular}


В третьей климатической зоне также в основном представлены станции, осуществляющие производство энергии за счет природного газа. В четвертой и пятой климатических зонах расположено наибольшее число станций, причем в четвертой зоне больше станций, где используется газ, тогда как в пятой тех, что работают на угле. Во второй климатической зоне в рамках выборки исследования расположено наименьшее число станций. С учетом заметных отличий в количестве станций, работающих на том или ином топливе, мы ввели в модель дополнительные экзогенные факторы в виде фиктивных переменных для контроля влияния фактора «вид используемого основного топлива». Если переменная имеет значение 1 , то станция использует в основном угольное топливо, если 0 - природный газ.

\section{3. ОПИСАТЕАЬНЫЕ СТАТИСТИКИ}

В рамках анализа были проанализированы техникоэкономические показатели деятельности 104 отечественных электростанций с 2015 по 2017 год.

Наиболее высокие значения КИТ показывают электростанции, расположенные в третьей климатической зоне (табл. 2). Наихудшие показатели демонстрируют станции в первой и пятой климатических зонах. В большинстве климатических зон значения КИТ для электростанций, использующих газ и уголь в качестве топлива, существенно разнятся. В неко-
Таблица 2

Коэффициент использования топлива в рамках климатических зон с детализацией электростанций по виду топлива, \%

\begin{tabular}{|c|c|c|c|c|c|c|}
\hline \multirow{2}{*}{ Год } & \multirow{2}{*}{ Вид топлива } & \multicolumn{5}{|c|}{ Климатическая зона } \\
\hline & & 1 & 2 & 3 & 4 & 5 \\
\hline \multirow{2}{*}{2015} & Газ & 47 & 61 & 70 & 60 & 46 \\
\hline & Уголь & - & 33 & 31 & 44 & 47 \\
\hline \multirow{2}{*}{2016} & Газ & 48 & 61 & 70 & 62 & 46 \\
\hline & Уголь & - & 32 & 33 & 44 & 48 \\
\hline \multirow{2}{*}{2017} & Газ & 48 & 61 & 70 & 62 & 47 \\
\hline & Уголь & - & 32 & 36 & 44 & 47 \\
\hline
\end{tabular}

торых случаях станции, использующие природный газ, могут показывать значения в 1,5-2,0 раза выше по сравнению со станциями, где в качестве топлива применяется уголь.

Таким образом, теоретическое описание регрессионной модели будет иметь вид:

$$
U=\beta_{0}+\beta_{1} \text { *климатическая_3она }+\beta_{2} \text { *вид_топлива }+\dot{\varepsilon} \text {, }
$$
где $\beta$ - соответствующий бета-коэффициент независимой переменной.

В рамках предлагаемого факторного анализа в качестве базовой ситуации рассматривается функционирование электростанции, расположенной в третьей климатической зоне (в основном регионы Северо-Западного и Центрального федеральных округов) и использующей газовое топливо.

Таблица 3

Влияние климатических факторов на коэффициент использования топлива на электростанциях

\begin{tabular}{|c|c|c|c|c|c|c|c|c|c|c|c|c|}
\hline \multirow[b]{2}{*}{ Показатель } & \multicolumn{3}{|c|}{ Все годы } & \multicolumn{3}{|c|}{2015} & \multicolumn{3}{|c|}{2016} & \multicolumn{3}{|c|}{2017} \\
\hline & 营 & 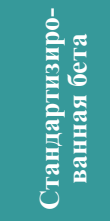 & 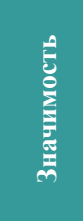 & 营 & 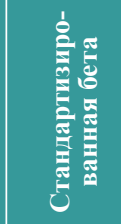 & $\begin{array}{l}\hat{E} \\
\text { हू } \\
\text { है } \\
\text { है }\end{array}$ & فํㄹㄹ & 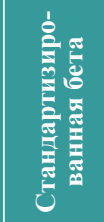 & 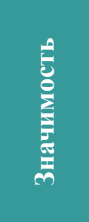 & 宽 & 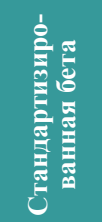 & 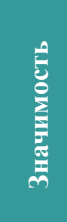 \\
\hline Константа & $71,832 * * *$ & - & 0,000 & $71,970 * * *$ & - & 0,000 & $72,074 * * *$ & - & 0,000 & $71,478 * * *$ & - &, 000 \\
\hline Climate 1 & $-14,667 * * *$ & $-0,286$ & 0,000 & $-16,051^{* * *}$ & $-0,319$ & 0,002 & $-14,486 * * *$ & $-0,281$ & 0,006 & $-13,352 * * *$ & $-0,256$ & ,008 \\
\hline Climate 2 & $-15,134 * * *$ & $-0,198$ & 0,000 & $-14,946^{* *}$ & $-0,194$ & 0,040 & $-15,458^{* *}$ & $-0,205$ & 0,033 & $-15,035^{* *}$ & $-0,197$ &, 033 \\
\hline Climate 4 & $-5,032 * *$ & $-0,160$ & 0,012 & $-5,629$ & $-0,177$ & 0,119 & $-5,811$ & $-0,183$ & 0,112 & $-3,782$ & $-0,123$ & ,264 \\
\hline Climate 5 & $-11,034^{* * *}$ & $-0,347$ & 0,000 & $-11,600^{* * *}$ & $-0,361$ & 0,006 & $-11,440^{* * *}$ & $-0,362$ & 0,006 & $-10,119^{* *}$ & $-0,320$ & ,012 \\
\hline $\begin{array}{l}\text { Вид основного } \\
\text { топлива }\end{array}$ & $-8,376^{* * *}$ & $-0,261$ & 0,000 & $-8,276^{* *}$ & $-0,255$ & 0,017 & $-7,933 * *$ & $-0,249$ & 0,023 & $-8,875^{* * *}$ & $-0,278$ & ,009 \\
\hline $\begin{array}{l}\text { Коэффициент } \\
\text { детерминации } R^{2}\end{array}$ & \multicolumn{3}{|c|}{0,245} & \multicolumn{3}{|c|}{0,249} & \multicolumn{3}{|c|}{0,24} & \multicolumn{3}{|c|}{0,247} \\
\hline $\begin{array}{l}\text { Скорректирован- } \\
\text { ный коэффици- } \\
\text { ент детермина- } \\
\text { ции }\end{array}$ & \multicolumn{3}{|c|}{0,233} & \multicolumn{3}{|c|}{0,21} & \multicolumn{3}{|c|}{0,2} & \multicolumn{3}{|c|}{0,21} \\
\hline $\begin{array}{l}\text { Коэффициент } \\
\text { Дарбина - Уот- } \\
\text { сона } D W\end{array}$ & \multicolumn{3}{|c|}{0,782} & \multicolumn{3}{|c|}{2,274} & \multicolumn{3}{|c|}{2,218} & \multicolumn{3}{|c|}{2,171} \\
\hline $\begin{array}{l}\text { Критерий Фише- } \\
\text { ра } F\end{array}$ & \multicolumn{3}{|c|}{$19,848 * * *$} & \multicolumn{3}{|c|}{$6,490 * * *$} & \multicolumn{3}{|c|}{$6,000 * * *$} & \multicolumn{3}{|c|}{$6,641 * * *$} \\
\hline $\begin{array}{l}\text { Количество } \\
\text { наблюдений } N\end{array}$ & \multicolumn{3}{|c|}{312} & \multicolumn{3}{|c|}{104} & \multicolumn{3}{|c|}{104} & \multicolumn{3}{|c|}{104} \\
\hline
\end{tabular}




\section{5. РЕЗУАЬТАТЫ}

В рамках анализа была построена модель, учитывающая данные за три отчетных периода (с 2015 по 2017 год), а также отдельные модели по каждому году (табл. 3). Подобный подход позволяет провести анализ чувствительности моделей к изменению числа наблюдений. Полученные результаты отличаются высокой надежностью, поскольку все модели показывают практически идентичные маржинальные эффекты для рассматриваемых переменных.

Итоги регрессионного анализа подтверждают наличие статистически значимой связи между климатическими условиями, видом топлива и КИТ. Расположенные в третьей климатической зоне электростанции, использующие газ в качестве топлива, в среднем имеют КИТ на уровне $71 \%$, те, что применяют уголь, - на 8,3 п.п. ниже.

Наихудшие результаты демонстрируют электростанции, расположенные во второй климатической зоне, - объекты генерации, находящиеся в Республике Калмыкия, Астраханской, Псковской и Ростовской областях (в среднем КИТ составляет $56,7 \%$ ). Почти идентичное отклонение от среднего значения КИТ станций третьей климатической зоны $(-14$ п.п.) прослеживается на электростанциях четвертой климатической зоны, куда включены субъекты Северо-Кавказского федерального округа, а также Краснодарский край и Калининградская область. На 11 п.п. от третьей климатической зоны значений КИТ ниже на электростанциях в пятой климатической зоне (в основном регионы Сибирского и Дальневосточного федеральных округов). К значению КИТ электростанций третьей климатической зоны ближе всегоэлектростанции четвертой климатической зоны (Поволжский и Уральский федеральные округа) (порядка 66\%).

Стоит отметить, что скорректированный коэффициент детерминации для всех моделей показывает значения от 0,2 до 0,23 . Значит, климатический фактор и фактор используемого топлива объясняют порядка $20 \%$ распределения значений КИТ. Таким образом, можно констатировать, что на $80 \%$ величина КИТ зависит от других факторов, не учтенных в рассматриваемой модели. На величину КИТ существенно влияет режимно-балансовая загрузка электростанции, поскольку она определяет долю когенерационной выработки электроэнергии - наиболее эффективного режима работы теплофикационных электростанций.

\section{6. ПРЕАЛОЖЕНИЯ ПО МОАЕАИ ЭТАЛОНИРОВАНИЯ ПОКАЗАТЕАЕЙ ТОПАИВНОЙ ЭФФЕКТИВНОСТИ ЭАЕКТРОСТАНЦИЙ}

На основе проведенного анализа сформированы концептуальные предложения по расчету эталонных значений КИТ для тепловых электростанций. На когенерационных электростанциях КИТ продиктован структурой используемого генерирующего оборудования (Чурарев, Маркова, 2017). Во многом различия по КПД и диапазонам оптимальной нагрузки (в соответствии с нормативно-технической докумен- тацией) приводят к разному соотношению электрической и тепловой мощности.

В рамках предлагаемого подхода расчет эталонных значений КИТ осуществляется исходя из исходных номинальных параметров режимов работы генерирующего оборудования станций, определяемых на основе нормативно-технической документации. Далее данный условно-эффективный показатель $U_{\text {эф }}$ корректируется с учетом вида топлива и климатической зоны. Таким образом, теоретическое описание предлагаемой модели эталонирования КИТ может иметь вид:

$$
U_{э . э}=w_{1} U_{\text {эф }}+w_{2} K_{\text {корр }},
$$

где $w_{n}$-весовое значение $n$-го фактора при расчете эталонного КИТ. Результаты регрессионного анализа указывают на то, что значение $w_{1}$ может равняться 0,8, a $w_{2}-0,2 ; U_{\text {эф }}-$ величина, определяемая исходя из анализа исходно-номинальных параметров режимов работы генерирующего оборудования на основе нормативно-технической документации по топливоиспользованию; $K_{\text {корр }}$ - коэффициент, отражающий влияние на КИТ природно-климатических факторов и вида топлива, определяется по формуле, основанной на результатах регрессионного анализа.

$$
K_{\text {корр }}=C+\beta_{\text {к }}-8,376 F_{\text {т }}
$$

Где $C$ - постоянный коэффициент, отражающий уровень КИТ в третьей климатической зоне, $C=71,832$ п.п. (уровень КИТ третьей климатической зоны принят как наилучший параметр в соответствии с расчетами (табл. 3)); $\beta_{k}$ - показатель, учитывающей фактор соответствующей климатической зоны (табл. 4$) ; F_{\text {т }}$ показатель, учитывающий вид топлива (если используется природный газ, то показатель принимается равным нулю, если уголь - единице), п.п.

Таблица 4

Климатические коэффициенты $\boldsymbol{\beta}_{\text {к }}$ для расчета $\boldsymbol{K}_{\text {корр }}$ при определении эталона КИТ для электростанций, П.п.

\begin{tabular}{|c|c|}
\hline зона & Коэффициент \\
\hline 1 & $-14,667$ \\
\hline 2 & $-15,134$ \\
\hline 3 & 0 \\
\hline 4 & $-5,032$ \\
\hline 5 & $-11,034$ \\
\hline
\end{tabular}

Применение подобного подхода позволит более точно определить расчетные эталонные значения КИТ для электростанций с учетом разнящихся природно-климатических условий и проектного вида топлива, сжигаемого на электростанциях.

\section{7. ЗАКАЮЧЕНИЕ}

Природно-климатические условия и вид используемого топлива являются значимыми экзогенными факторами, 
влияющими на технико-экономические показатели работы электростанций в части эффективности топливоиспользования. Соответствующие факторы рекомендуется учитывать при построении аналитических моделей по эталонированию топливной эффективности электростанций в России.

Предполагается, что расчетные значения эталонов будут носить условно-целевой характер, поскольку будут учтены системные ограничения и фактические ремонтные программы, определенные на основании только одного-трех отчетных лет. В перспективе необходима актуализация соответствующих параметров с учетом изменения ограничений.

Среди будущих направлений исследований в данной области можно отметить обоснование расчета эталонных значений КИТ на основе нормативно-технической документации по топливоиспользованию. Также необходимо детально изучить потенциальный положительный эффект от внедрения различных энергоэффективных технологий на КИТ тепловых электростанций и их эффективность в целом.

\section{8. ИНФОРМАЦИЯ О СПОНСОРСТВЕ}

Данная статья была подготовлена в рамках выполнения научно-исследовательской работы № 18/0411.3070390019.24 1/09/210 в интересах Министерства энергетики Российской Федерации.

\section{АИТЕРАТУРА}

1. Веселов Ф.В., Волкова Е.А., Курилов А.Е. и др. (2010). Методы и инструментарий прогнозирования развития электроэнергетики // Известия Российской академии наук. Энергетика. №. 4. С. 82-94.

2. Волкова Е.А., Макарова А.С., Хоршев А. А.и др. (2010). Исследование эффективности развития теплофикации в России // Известия Российской академии наук. Энергетика. №. 4. С. 95-110.

3. Гаврилова А.А. (2015).Организация управления энергетическим производством на основе комплексных критериев деятельности // Вестник Волжского университета им. В.Н. Татищева. № 1. С. 11-16.

4. Постановление Правительства РФ «Об определении ценовых параметров торговли мощностью на оптовом рынке электрической энергии и мощности» от 13.04.2010 №238 // Российская газета. 2010. 14 апр. URL: https:// rg.ru/2010/06/04/elektro-site-dok.html.

5. Распоряжение Правительства РФ от 19.04.2018 № 703-р «Об утверждении комплексного плана мероприятий по повышению энергетической эффективности экономики Российской Федерации» // КонсультантПлюс. URL: http:// www.consultant.ru/document/cons_doc LAW 296507/.

6. Теплоэнергетика и централизованное теплоснабжение России в 2015-2016 годы: Информационно-аналитический доклад (2018) // Минэнерго России. URL: https:// minenergo.gov.ru/node/10850/80685.
7. Федеральный закон «О теплоснабжении» от 27.07.2010 г. № 190-Ф3// Российская газета.30 июля. URL: https:// rg.ru/2010/07/30/teplo-dok.html.

8. Филиппов С.П., Дильман М.Д. (2014). Перспективы использования когенерационных установок при реконструкции котельных // Промышленная энергетика. №4. C. 7-11.

9. Чурашев В.Н. (2016). Каким быть энергообеспечению Новосибирской области? // Интерэкспо Гео-Сибирь. T. 3. № 3. С. 60-65.

10. Чурашев В.Н., Маркова В.М. (2017). Малая распределенная энергетика - новый вектор развития генерации в сибирских регионах // Интерэкспо Гео-Сибирь. Т. 3, №2. C. 75-81.

11. Allan G., Eromenko I., Gilmartin M. et al. (2015). The economics of distributed energy generation: A literature review // Renewable and Sustainable Energy Reviews. T. 42. P. 543-556.

12. Jiang-Jiang W., Chun-Fa Z., You-Yin J. (2010). Multi-criteria analysis of combined cooling, heating and power systems in different climate zones in China // Applied Energy. T. 87. №4. P. 1247-1259.

13. Methods for Calculating CHP Efficiency ( [s.a.]) // United States Environmental Protection Agency. URL: https:// www.epa.gov/chp/methods-calculating-chp-efficiency.

14. Suganthi L., Samuel A.A. (2012). Energy models for demand forecasting - a review // Renewable and sustainable energy reviews. T. 16. №2. P. 1223-1240.

\section{REFERENCES}

1. Veselov, F. V., Volkova, E. A., Kurilov, A. E. et al. (2010). Metody i instrumentarij prognozirovaniya razvitiya elektroenergetiki // Izvestiya Rossijskoj akademii nauk. Energetika. 4:82-94 [Veselov F. V., Volkova E.A., Kurilov A.E. i dr. (2010) Electric energy development prediction methods and model. Russian academy of science bulletin. Energy. 4:82-94. (In Russ.).].

2. Volkova, E. A., Makarova, A. S., Khorshev, A. A. et al. (2010). Issledovanie effektivnosti razvitiyateplofikacii $\mathrm{V}$ Rossii // IzvestiyaRossijskoj akademii nauk Energetika. 4:95-110. [Volkova E.A., Makarova A.S., Horshev A.A. et al. (2010) A study of heat supply efficiency in Russia. Russian academy of science bulletin. Energy. 4:95-110. (In Russ.).].

3. Gavrilova, A. A. (2015). Organizaciya upravleniya energeticheskim proizvodstvom na osnove kompleksnykh kriteriev deyatelnosti // Vestnik Volzhskogo universiteta im. V.N. Tatishcheva. 1:11-16. [Gavrilova A.A. (2015). Managing electric energy production using composite indicators. Bulletin of Tatishev Volga University. 1:11-16. (In Russ.).].

4. Postanovlenie Pravitelstva RF “Ob opredelenii cenovykh parametrov torgovli moshchnostyu na optovom rynke elektricheskoj energii i moshchnosti” ot 13.04.2010 № 238 // Rossijskaya gazeta. 14 apr. [Act of Government of the Russian Federation № 238 "About setting price characteristics for power trade deals on the wholesale electricity market" 
from 13.04.2010. Rossijskayagazeta. April 14 (In Russ.).]. https://rg.ru/2010/06/04/elektro-site-dok.html.

5. RasporyazheniePravitelstva RF ot 19.04.2018. № 703-r “ $\mathrm{Ob}$ utverzhdenii kompleksnogo plana meropriyatij po povysheniyu energeticheskoj effektivnosti ekonomiki Rossijskoj Federacii" // KonsultantPlyus [Act of Government of the Russian Federation № 703 “About the Master plan for increasing energy efficiency of the Russian economy” from 19.04.2018. Consultant Plus. (In Russ.).]. http://www.consultant.ru/document/cons_doc_LAW_296507/.

6. Teploenergetika $\overline{\mathrm{i}}$ centralizovannoe teplosnabzhenie Rossii v 2015-2016 gody: Informacionno-analiticheskij doklad (2018) // Minenergo Rossii [Thermal energy and centralized heat supply in Russia 2015-2016: Analytical report. Russian Ministry of Energy. (In Russ.).]. https:// minenergo.gov.ru/node/10850/80685.

7. Federalnyj zakon "O teplosnabzhenii” ot 27.07.2010 g № 190-FZ // Rossijskayagazeta. 30 iyulya [Federal Law № 190-FZ “About thermal power supply” from 27.07.2010. Rossijskayagazeta. July 30. (In Russ.).].https:// rg.ru/2010/07/30/teplo-dok.html.

8. Filippov, S. P., Dilman, M. D. (2014). Perspektivy ispolzovaniya kogeneracionnykh ustanovok pri rekonstrukcii kotelnykh // Promyshlennaya energetika. 4:7-11. [Filippov, S. P., Dil'man, M. D. (2014). Prospects for using CHP technologies in boiler construction. Industrial energy. 4:7-11. (In Russ.).].
9. Churashev, V. N. (2016). Kakim byt energoobespecheniyu Novosibirskoj oblasti // Interekspo Geo-Sibir. 3 (3):60-65. [Churashev V.N. (2016). What are the possibilities for power supply in Novosibirsk region? Interexpo Geo-Sibiria. 3 (3):60-65. (In Russ.).].

10. Churashev, V. N., Markova, V. M. (2017). Malaya raspredelennaya energetika - novyj vector razvitiya generacii $\mathrm{v}$ sibirskikh regionakh // Interekspo Geo-Sibir. 3 (2):75-81. [Churashev V.N., Markova V.M. (2017). Distribution energy systems - a new pathway of power generation in Siberian regions. Interexpo Geo-Sibiria. 3 (2):75-81. (In Russ.).].

11. Allan, G., Eromenko, I., Gilmartin, M. et al. (2015). The economics of distributed energy generation: A literature review. Renewable and Sustainable Energy Reviews. 42:543-556.

12. Jiang-Jiang, W., Chun-Fa, Z., You-Yin, J. (2010). Multi-criteria analysis of combined cooling, heating and power systems in different climate zones in China. Applied Energy. 87 (4):1247-1259.

13. Methods for Calculating CHP Efficiency ( [s.a.]). United States Environmental Protection Agency. https:// www.epa.gov/chp/methods-calculating-chp-efficiency.

14. Suganthi, L., Samuel, A. A. (2012). Energy models for demand forecasting - a review. Renewable and sustainable energy reviews. 16 (2):1223-1240. 


\section{ИНФОРМАЦИЯ ОБ АВТОРАХ}

\section{И.Ю. Золотова}

Директор Центра отраслевых исследований и консалтинга, ФГОБУ ВО «Финансовый университет при Правительстве Российской Федерации». Область научных интересов: экономика электроэнергетики, ценообразование, инвестиционная деятельность в электроэнергетике, система государственного регулирования естественных монополий.

$\triangle \quad$ E-mail: IYZolotova@fa.ru

\section{В.А. Карле}

Заместитель директора Центра отраслевых исследований и консалтинга, ФГОБУ ВО «Финансовый университет при Правительстве Российской Федерации». Область научных интересов: система государственного регулирования естественных монополий, ценообразование, модели прогнозирования цен, электроэнергетика и иные инфраструктурные отрасли.

E-mail:VAKarle@fa.ru

\section{Н.А. Осокин}

Заместитель директора Центра отраслевых исследований и консалтинга, Финансовый университет при Правительстве РФ. Область научных интересов: эконометрический анализ, управление эффективностью и результативностью, экономика спорта. E-mail: NAOsokin@fa.ru

\section{ABOUT THE AUTHORS}

\section{IrinaYu. Zolotova}

Director at the Center of Sectoral Research and Consulting, Financial University under the Government of the Russian Federation. Research interests: electric energy economics, pricing, investments in electric energy, government regulation of natural monopolies.

$\triangle$ E-mail: IYZolotova@fa.ru

\section{Vadim A. Karle}

Deputy director at the Center of Sectoral Research and Consulting, Financial University under the Government of the Russian Federation. Research interests: government regulation of natural monopolies, pricing, price prediction modelling, electric energy and other infrastructure sectors.

E-mail:VAKarle@fa.ru

\section{Nikita A. Osokin}

Deputy director at the Center of Sectoral Research and Consulting, Financial University under the Government of the Russian Federation. Research interests: econometric analysis, performance management, sports economics.

E-mail: NAOsokin@fa.ru 